\title{
Anti-inflammatory effects of escin are correlated with the glucocorticoid receptor/NF-кB signaling pathway, but not the COX/PGF2 $\alpha$ signaling pathway
}

\author{
HONGSHENG WANG* , LEIMING ZHANG* ${ }^{*}$ NA JIANG, ZHENHUA WANG, \\ YATING CHONG and FENGHUA FU
}

Department of Pharmacology, School of Pharmacy, Yantai University, Yantai, Shandong 264005, P.R. China

Received February 22, 2013; Accepted May 15, 2013

DOI: $10.3892 /$ etm.2013.1128

\begin{abstract}
In China, escin has been widely used in the clinic as a potent anti-inflammatory drug. Previous studies have indicated that escin exerts its anti-inflammatory effect by enhancing the release of glucocorticoids (GCs) and prostaglandin-F2 $\alpha$ (PGF $2 \alpha$ ), and this has been documented in the drug description. However, our previous studies demonstrated that escin did not increase the secretion of GCs, but instead elevated the protein expression of the GC receptor (GR), which may have repressed nuclear factor $(\mathrm{NF})-\kappa \mathrm{B}-$ mediated gene expression. The aim of this study was to determine the functions of $\mathrm{NF}-\kappa \mathrm{B}$ and PGF2 $\alpha$ with regard to the anti-inflammatory effect of escin. We investigated the anti-inflammatory effects of dexamethasone, diclofenac and escin against carrageenan-induced paw edema in rats, and observed that escin exerted a GC-like anti-inflammatory effect. In addition, we studied the role of PGF $2 \alpha$ in the anti-inflammatory effect exerted by escin in an acetic acid-induced capillary permeability model in mice. The results revealed that the coadministration of escin and diclofenac, a potent prostaglandin-synthesis inhibitor, did not affect the anti-inflammatory effect of escin. Furthermore, we investigated the function of $\mathrm{NF}-\kappa \mathrm{B}$ with regard to the anti-inflammatory effect exerted by escin in lipopolysaccharide (LPS)-treated mice, and demonstrated that escin significantly inhibited the expression of $\mathrm{NF}-\kappa \mathrm{B}$. These results suggest that escin has a GC-like anti-inflammatory effect, and that its mechanisms may be correlated with the GC receptor/NF- $\kappa \mathrm{B}$ signaling pathway, but not the COX/PGF $2 \alpha$ signaling pathway.
\end{abstract}

Correspondence to: Professor Fenghua Fu, Department of Pharmacology, School of Pharmacy, Yantai University, 32 Qingquan Road, Yantai, Shandong 264005, P.R. China

E-mail: fufenghua@sohu.com

${ }^{*}$ Contributed equally

Key words: escin, inflammation, prostaglandin-F2 $\alpha$, nuclear factor- $\kappa \mathrm{B}$, glucocorticoid

\section{Introduction}

Escin is the predominant active constituent of Aesculus hippocastanum seed extract, which is a triterpene saponin mixture consisting of A, B, C and D escin. Accumulating experimental results in previous studies have suggested that escin exerts potent anti-inflammatory and anti-edematous effects (1-4); consequently, escin is, at present, widely used in the clinic.

The anti-inflammatory mechanisms of escin have been documented in the description of the drug as being due to an increase in the secretion of glucocorticoids (GCs) and prostaglandin-F2 $\alpha$ (PGF2 $\alpha$ ). However, our previous results demonstrated that the anti-inflammatory effect of escin was not dependent on the release of GCs, and, moreover, no immunosuppressive effects were observed with GCs (5). We further identified that the anti-inflammatory effect was correlated with an elevation in the expression level of GC receptor (GR) protein (4).

GCs exert anti-inflammatory effects by binding to GRs, which, upon activation, translocate to the nucleus and inhibit proinflammatory transcription factors, such as nuclear factor- $\kappa \mathrm{B}(\mathrm{NF}-\kappa \mathrm{B})(6)$. It has been reported that escin may aid tumor suppression by downregulating $\mathrm{NF}-\kappa \mathrm{B}(7,8)$. However, whether the anti-inflammatory effects of escin are mediated by the GR/NF- $\kappa$ B signaling pathway has remained undetermined.

PGF $2 \alpha$ is a member of the prostaglandin (PG) family that is important in the modulation of inflammation. PGF2 $\alpha$ differs from other PGs, such as PGF1 and PGE2, in that it is able to contract blood vessels, facilitate venous return and improve lymph transport, and thus counteracts the exudation and edema induced by inflammatory mediators (9-13). It has been indicated that escin is able to increase the secretion of PGF $2 \alpha$ from vascular endothelial cells (14-16); however, it has not been determined whether the anti-inflammatory mechanisms of escin occur as a result of this increased secretion of PGF $2 \alpha$.

In the present study, we investigated the GC-like anti-inflammatory effects of escin, and studied the functions of PGF $2 \alpha$ and NF- $\kappa$ B in these effects.

\section{Materials and methods}

Animals. Male Swiss mice (weight, 18-22 g) and male Wistar rats (weight, 160-200 g) were purchased from the Experimental 
Animal Center of Shandong Luye Pharmaceutical Co., Ltd. (Yantai, China). All experimental procedures performed in this study were executed in accordance with the Yantai University (Yantai, China) guidelines for the care and use of laboratory animals, and were approved by the ethics committee of the university. The animals were housed in diurnal lighting conditions (12/12 h) and were allowed free access to food and water.

Drugs and materials. The escin used in the experiments was in the form of sodium aescinate, obtained as a lyophilized powder in a $5 \mathrm{mg}$ vial (batch no. 201004144; Shandong Luye Pharmaceutical Co., Ltd.). Diclofenac sodium tablets were purchased from the Sichuan Shuzhong Pharmaceutical Group (batch no. 0908032; Guanghan, China), and diclofenac sodium injections were obtained from the Chongqing Laimei Pharmaceutical Co., Ltd. (batch no. 20100805; Chongqing, China). The dexamethasone sodium phosphate injections used in the study were purchased from the Tianjin Pharmaceutical Group Corp. (batch no. 1009231; Hedong, China), while the $\lambda$-carrageenan was purchased from Sigma-Aldrich (batch no. 1408463V; Shanghai, China). The Escherichia coli O55:B5 lipopolysaccharide (LPS) was purchased from Sigma-Aldrich. The primary and secondary antibodies to NF- $\kappa \mathrm{B}$ were obtained from the Beyotime Institute of Biotechnology (Haimen, China).

Carrageenan-induced paw edema model. Forty Wistar rats were randomly divided into control, dexamethasone (4 mg/kg), escin $(1.8 \mathrm{mg} / \mathrm{kg})$ and diclofenac $(6 \mathrm{mg} / \mathrm{kg})$ groups. Carrageenan $(0.1 \mathrm{ml}, 1 \% \mathrm{w} / \mathrm{v})$ was injected into the right-hind paw (sub-plantar) of the rats, and the corresponding drugs were administered (intragastrically for diclofenac, and intravenously for dexamethasone and escin) $30 \mathrm{~min}$ later. The paw volume was measured with a hydroplethysmometer (Shandong Academy of Medical Sciences, Jinan, China) prior to the irritant injection, and at selected intervals $(1,2,4,6,8,12$, 18 and $24 \mathrm{~h}$ ) subsequent to the administration of the drugs. The results are expressed as the increase in paw volume ( $\mathrm{ml}$ ), which was calculated by subtracting the basal volume.

LPS-induced inflammatory model. Twenty-one mice were assigned to seven groups: the control, LPS, escin $(3.6 \mathrm{mg} / \mathrm{kg})$, LPS plus dexamethasone $(4.0 \mathrm{mg} / \mathrm{kg})$ and three LPS plus escin groups $(0.9,1.8$ and $3.6 \mathrm{mg} / \mathrm{kg})$. The corresponding drugs or saline were administered intravenously $2 \mathrm{~h}$ prior to the LPS treatment ( $40 \mathrm{mg} / \mathrm{kg}$, intravenously). Six hours subsequent to the LPS injection, fresh liver tissues $(60 \mathrm{mg})$ were homogenized in an ice-cold lysis buffer (Beyotime Institute of Biotechnology), with a 1:100 volume of phenylmethylsulfonyl fluoride (PMSF). The homogenate was centrifuged at $14,000 \mathrm{x} \mathrm{g}$ for $5 \mathrm{~min}$ at $4^{\circ} \mathrm{C}$, and then $50 \mu \mathrm{g}$ of the proteins obtained were separated using $10 \%$ sodium dodecyl sulfate-polyacrylamide gel electrophoresis (SDS-PAGE) gels. The blots were subsequently transferred to nitrocellulose membranes, and incubated in blocking buffer $(5 \%$ skimmed milk in Tris-buffered saline solution with Tween 20), prior to further incubation with rabbit polyclonal anti-NF- $\kappa$ B p65 in diluent buffer (both purchased from Beyotime Institute of Biotechnology) overnight at $4{ }^{\circ} \mathrm{C}$ (1:1,000 dilution). Following this, the blots were incubated with the corresponding secondary antibody conjugated with horseradish peroxidase, for $2 \mathrm{~h}$ at room temperature.
Anti- $\beta$-actin antibody (Beyotime Institute of Biotechnology) was used as the loading control, and the blots were then developed by enhanced chemiluminescence (Amersham Biosciences, Piscataway, NJ, USA). Densitometric techniques were applied to quantify the protein band densities (ImageJ software; Rasband WS, US National Institute of Health, Bethseda, MD, USA), which were expressed as relative densitometric units of the corresponding $\beta$-actin control.

Acetic acid-induced capillary permeability model. One hundred and twenty mice were randomly divided into four groups: the control, escin $(3.6 \mathrm{mg} / \mathrm{kg})$, diclofenac $(3.6 \mathrm{mg} / \mathrm{kg})$ and escin plus diclofenac (1.8 and $3.6 \mathrm{mg} / \mathrm{kg}$, respectively) groups. The mice were treated with the same volume of normal saline solution or drug via the tail vein. At $10 \mathrm{~min}$, and $0.5,1,2,4,6,8,10,16$ and $24 \mathrm{~h}$ subsequent to the drug administration, three mice in each group were injected intravenously with $0.2 \mathrm{ml} 1.0 \%$ Evans Blue (Sigma, St. Louis, MO, USA) in saline solution via the tail vein, before $0.2 \mathrm{ml}$ $1 \%(\mathrm{v} / \mathrm{v})$ acetic acid in saline solution was injected intraperitoneally. Twenty minutes later, the mice were sacrificed, and the viscera were exposed and irrigated with $3 \mathrm{ml}$ distilled water, which was then filtered through glass wool into $10 \mathrm{ml}$ volumetric flasks. Each flask was made up to a $10 \mathrm{ml}$ final volume with distilled water, and $0.1 \mathrm{ml} \mathrm{NaOH}$ solution $(0.1 \mathrm{M})$ was added. The absorption of the final solution was measured at $590 \mathrm{~nm}$ using an automated enzyme-linked immunosorbent assay (ELISA) reader (Synergy ${ }^{\mathrm{TM}}$ HT Multi-Mode Microplate Reader; BioTek Instruments, Inc., Winooski, VT, USA). The inhibition level was calculated using the following formula: Inhibition $(\%)=(1-\mathrm{Ac} / \mathrm{At}) \times 100$, where Ac and At are the average absorptions of the saline-treated control group and the drug-treated group, respectively.

Statistical analysis. All data are expressed as the mean \pm standard error of the mean (SEM). The statistical significance of differences between the groups was determined by analysis of variance (ANOVA), followed by the Student's t-test. $\mathrm{P}<0.05$ was considered to indicate a statistically significant difference.

\section{Results}

Effects of escin on carrageenan-induced paw edema in rats. Treatment with escin $(1.8 \mathrm{mg} / \mathrm{kg})$ significantly inhibited the development of paw edema from 4 to $24 \mathrm{~h}$ following administration $(\mathrm{P}<0.05)$. Similarly, dexamethasone $(4.0 \mathrm{mg} / \mathrm{kg})$ significantly reduced the carrageenan-induced paw edema from 4 to $12 \mathrm{~h}$ following administration $(\mathrm{P}<0.05)$. In addition, the mean values of the swelling rate in the dexamethasone group at 18 and $24 \mathrm{~h}(12.1 \pm 4.7$ and $12.0 \pm 4.6 \%$, respectively) were equivalent to those of the escin group (11.7 \pm 3.9 and $11.6 \pm 3.6 \%$, respectively). Unlike escin or dexamethasone, diclofenac $(6.0 \mathrm{mg} / \mathrm{kg})$ significantly inhibited the development of paw edema from 2 to $6 \mathrm{~h}$ following administration ( $\mathrm{P}<0.05$; Fig. 1).

Effects of escin on $N F-\kappa B$ protein expression in LPS-treated mice. The administration of LPS increased the protein expression level of the NF- $\kappa \mathrm{B}$ p65 subunit significantly $(\mathrm{P}<0.01)$, unlike the administration of escin alone, which did not significantly affect the expression of the p65 subunit in the livers 


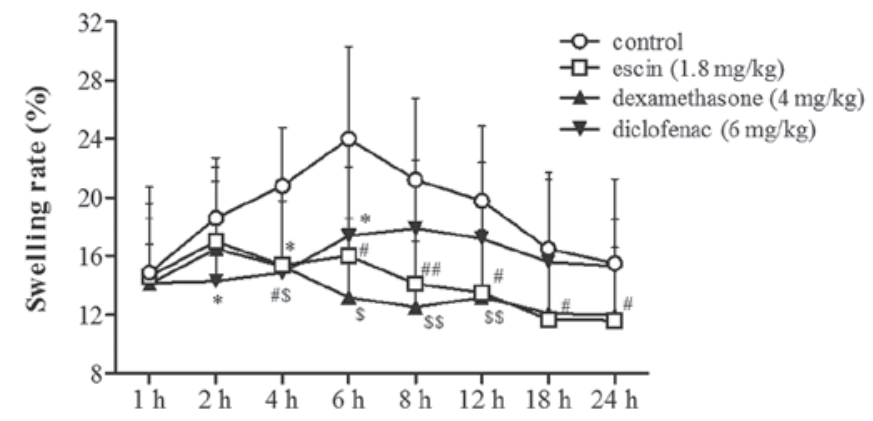

Figure 1. Time-effect curves of escin, dexamethasone and diclofenac in carrageenan-induced paw edema in rats. Results are expressed as the mean \pm standard error of the mean. ${ }^{*} \mathrm{P}<0.05$, diclofenac compared with the control group; ${ }^{\#} \mathrm{P}<0.05$ and ${ }^{\# \#} \mathrm{P}<0.01$, escin compared with the control group; ${ }^{\$} \mathrm{P}<0.05$ and ${ }^{\$} \mathrm{P}<0.01$, dexamethasone compared with the control group.

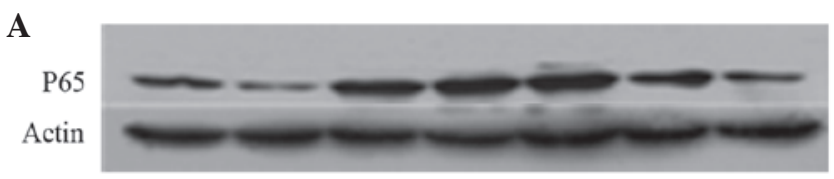

B

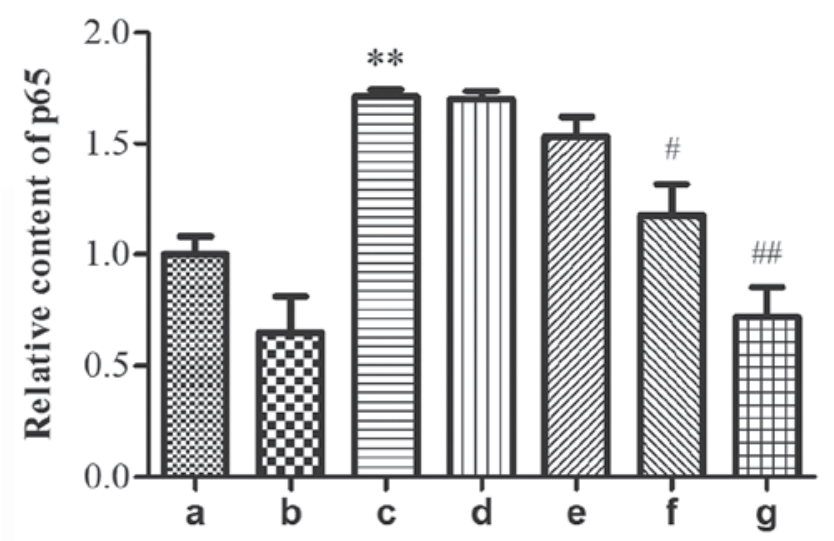

Figure 2. Effect of escin on the nuclear factor- $\kappa \mathrm{B}(\mathrm{NF}-\kappa \mathrm{B}) \mathrm{p} 65$ protein expression level in LPS-treated mice. A) Protein expression of $\mathrm{p} 65$, relative to the $\beta$-actin control. B) Relative intensity of the $\mathrm{p} 65$ protein band, normalized to $\beta$-actin. The mice were assigned to seven groups: (a) control; (b) escin (3.6 $\mathrm{mg} / \mathrm{kg}$ ); (c) LPS; (d) LPS plus dexamethasone $(4.0 \mathrm{mg} / \mathrm{kg})$; and (e-g) LPS plus escin $(0.9,1.8$ and $3.6 \mathrm{mg} / \mathrm{kg}$, respectively). The results are presented as the mean \pm standard error of the mean of three independent experiments. ${ }^{* * *} \mathrm{P}<0.01$, compared with the control group; ${ }^{\#} \mathrm{P}<0.05$ and ${ }^{\# \#} \mathrm{P}<0.01$, compared with the LPS group.

of the mice $(\mathrm{P}>0.05)$. In the LPS plus escin groups, 1.8 and $3.6 \mathrm{mg} / \mathrm{kg}$ escin significantly inhibited the protein expression of the NF- $\kappa \mathrm{B}$ p 65 subunit that was induced by the LPS administration ( $\mathrm{P}<0.05$ and $\mathrm{P}<0.01$, respectively; Fig. 2).

Anti-inflammatory effects of escin plus diclofenac on a mouse model of acetic acid-induced capillary permeability. Diclofenac $(3.6 \mathrm{mg} / \mathrm{kg})$ significantly inhibited the acetic acid-induced capillary permeability from $10 \mathrm{~min}$ to $8 \mathrm{~h}$ following administration. A similar effect was observed with escin $(3.6 \mathrm{mg} / \mathrm{kg})$, which significantly inhibited the capillary permeability from 8 to $24 \mathrm{~h}$ following administration. The coadministration of escin and diclofenac $(1.8$ and $3.6 \mathrm{mg} / \mathrm{kg}$,

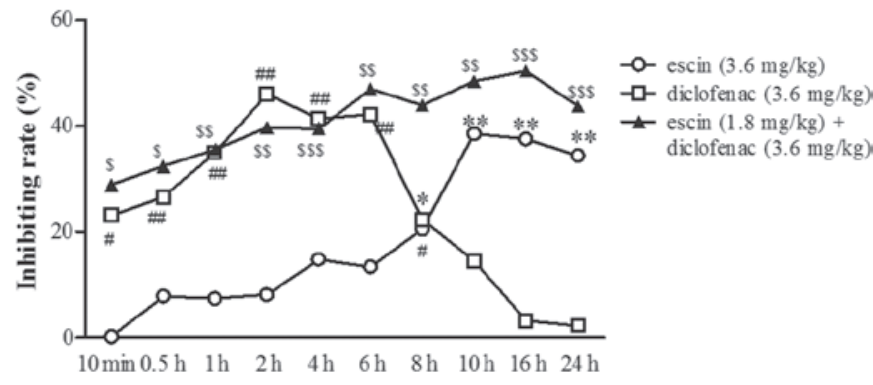

Figure 3. Effect of diclofenac on the anti-inflammatory activity of escin in a mouse model of acetic acid-induced capillary permeability. The results are expressed as absorption inhibiting rates, and are compared with the control group. ${ }^{*} \mathrm{P}<0.05$ and ${ }^{* *} \mathrm{P}<0.01$, escin compared with the control group; ${ }^{*} \mathrm{P}<0.05$ and ${ }^{\# \#} \mathrm{P}<0.01$, diclofenac compared with the control group; ${ }^{\$} \mathrm{P}<0.05,{ }^{\$ \$} \mathrm{P}<0.01$ and ${ }^{\$ \$} \mathrm{P}<0.001$, coadministration of escin and diclofenac compared with the control group.

respectively) significantly inhibited the capillary permeability from $10 \mathrm{~min}$ to $24 \mathrm{~h}$ following administration (Fig. 3).

\section{Discussion}

The GR is a member of the nuclear receptor family that is activated by GCs. Upon activation, the GR translocates to the nucleus and inhibits proinflammatory transcription factors, such as $\mathrm{NF}-\kappa \mathrm{B}$, thereby reducing the inflammatory reaction $(17,18)$.

In a previous study, we demonstrated that escin elevated the expression of the GR, and reduced the liver injury induced by endotoxins in mice (4). However, it has remained unclear whether the anti-inflammatory mechanism of escin involves the GR/NF- $\kappa \mathrm{B}$ signaling pathway. In the present study, we showed that escin exhibited potent GC-like anti-inflammatory effects against carrageenan-induced paw edema and acetic acid-induced capillary permeability. In addition, we demonstrated that escin significantly inhibited the expression of p65 in the livers of mice with LPS-induced sepsis. These results indicate that the anti-inflammatory effects of escin may occur through the GR/NF- $\mathrm{B}$ pathway.

PGs are generated from the action of cyclooxygenases (COXs) on arachidonic acid. Diclofenac, a non-steroidal anti-inflammatory drug, potently inhibits the activity of COXs (19) and reduces the arachidonic acid level in plasma (20), and thus greatly inhibits the biosynthesis of PGs, such as PGD, PGE and PGF. An increase in PGF $2 \alpha$ secretion from vascular endothelial cells has traditionally been considered as a critical factor for the anti-inflammatory effect of escin, and this has been documented in the description of the drug. However, in our present study, the results demonstrated that diclofenac did not exert any negative influence on the anti-inflammatory effect of escin. This indicated that the effect exerted by escin was not dependent on the increase in PGF $2 \alpha$ secretion.

With the results from our present and previous studies, we may conclude that escin exhibits potent glucocorticoid-like anti-inflammatory effects, the mechanism of which may involve GR/NF- $\mathrm{B}$ pathway; however, the effects do not depend on an increase in PGF $2 \alpha$ secretion. These results may be useful in the further elucidation of the anti-inflammatory mechanism of escin, and to rationalize its clinical application. 


\section{Acknowledgments}

This study was supported by the Taishan Scholar Project, the National Natural Science Foundation of China (grant no. 30772760), the Foundation for Outstanding Middle-age and Young Scientists (No. BS2011YY061) and the Doctoral Foundation of Yantai University (grant no. YX11B31).

\section{References}

1. Fu F, Hou Y, Jiang W, Wang R and Liu K: Escin: inhibiting inflammation and promoting gastrointestinal transit to attenuate formation of postoperative adhesions. World J Surg 29: $1614-1620,2005$

2. Zhang L, Fu F, Zhang X, Zhu M, Wang T and Fan H: Escin attenuates cognitive deficits and hippocampal injury after transient global cerebral ischemia in mice via regulating certain inflammatory genes. Neurochem Int 57: 119-127, 2010.

3. Xin W, Zhang L, Fan H, Jiang N, Wang T and Fu F: Escin attenuates acute lung injury induced by endotoxin in mice. Eur J Pharm Sci 42: 73-80, 2011.

4. Jiang N, Xin W, Wang T, Zhang L, Fan H, Du Y, Li C and Fu F: Protective effect of aescin from the seeds of Aesculus hippocastanum on liver injury induced by endotoxin in mice. Phytomedicine 18: 1276-1284, 2011.

5. Zhang L, Wang H, Fan H, Wang T, Jiang N, Yu P and Fu F: The potent anti-inflammatory agent escin does not increase corticosterone secretion and immune cell apoptosis in mice. Fitoterapia 82: 861-867, 2011

6. Rhen T and Cidlowski JA: Antiinflammatory action of glucocorticoids - new mechanisms for old drugs. N Engl J Med 353: $1711-1723,2005$

7. Wang YW, Wang SJ, Zhou YN, Pan SH and Sun B: Escin augments the efficacy of gemcitabine through down-regulation of nuclear factor- $\mathrm{\kappa B}$ and nuclear factor- $\kappa \mathrm{B}$-regulated gene products in pancreatic cancer both in vitro and in vivo. J Cancer Res Clin Oncol 138: 785-797, 2012.

8. Harikumar KB, Sung B, Pandey MK, Guha S, Krishnan S and Aggarwal BB: Escin, a pentacyclic triterpene, chemosensitizes human tumor cells through inhibition of nuclear factor-kappaB signaling pathway. Mol Pharmacol 77: 818-827, 2010.
9. Williams PB and Joyner JH: Response of peripheral collateral arteries in the dog to prostaglandins E1, E2, F2 alpha, and I2 (prostacyclin). J Cardiovasc Pharmacol 4: 784-790, 1982.

10. Emerson TE Jr, Jelks GW, Daugherty RM Jr and Hodgman RE: Effects of prostaglandin E1 and F2 alpha on venous return and other parameters in the dog. Am J Physiol 220: 243-249, 1971.

11. Uski TK, Andersson KE, Brandt L and Ljunggren B: Characterization of the prostanoid receptors and of the contractile effects of prostaglandin F2 alpha in human pial arteries. Acta Physiol Scand 121: 369-378, 1984.

12. Amann-Vesti BR, Gitzelmann G, Koppensteiner R and Franzeck UK: Isoprostane 8-epi-prostaglandin F2 alpha decreases lymph capillary pressure in patients with primary lymphedema. J Vasc Res 40: 77-82, 2003.

13. Sinzinger H, Oguogho A and Kaliman J: Isoprostane 8-epi-prostaglandin F2 alpha is a potent contractor of human peripheral lymphatics. Lymphology 30: 155-159, 1997.

14. Longiave D, Omini C, Nicosia S and Berti F: The mode of action of aescin on isolated veins: relationship with PGF2 alpha. Pharmacol Res Commun 10: 145-152, 1978.

15. Berti F, Omini C and Longiave D: The mode of action of aescin and the release of prostaglandins. Prostaglandins 14: 241-249, 1977.

16. Carrasco OF and Vidrio H: Endothelium protectant and contractile effects of the antivaricose principle escin in rat aorta. Vascul Pharmacol 47: 68-73, 2007.

17. Lu NZ, Wardell SE, Burnstein KL, Defranco D, Fuller PJ, Giguere V, Hochberg RB, McKay L, Renoir JM, Weigel NL, et al: International Union of Pharmacology. LXV. The pharmacology and classification of the nuclear receptor superfamily: glucocorticoid, mineralocorticoid, progesterone, and androgen receptors. Pharmacol Rev 58: 782-797, 2006.

18. Mckay LI and Cidlowski JA: Molecular control of immune/inflammatory responses: interactions between nuclear factor-kappa B and steroid receptor-signaling pathways. Endocrine Rev 20: 435-459, 1999.

19. Ku EC, Wasvary JM and Cash WD: Diclofenac sodium (GP 45840, Voltaren), a potent inhibitor of prostaglandin synthetase. Biochem Pharmacol 24: 641-643, 1975.

20. Ku EC, Kothari H, Lee W, Kimble EF and Liauw LH: Effects of diclofenac sodium on arachidonic acid metabolism. Agents Actions Suppl 17: 189-193, 1985. 